\title{
Analisis Faktor yang Mendorong Konsumen Memilih Hotel Melalui Situs Traveloka.com
}

\section{Analysis of Factors Affect Consumer Decisions in Choosing Hotels Through the Traveloka.com}

\author{
Muhammad Ashoer1)*, Munawir Nasir Hamzah'2), \& Fahrina Mustafa ${ }^{3)}$ \\ 1), 2) Jurusan Manajemen, Fakultas Ekonomi, Universitas Muslim Indonesia, Indonesia \\ 3) Jurusan Manajemen, Fakultas Ekonomi, Universitas Hasanuddin, Indonesia
}

*Corresponding Email: muhammad.ashur@umi.ac.id

\begin{abstract}
Abstrak
Bermodalkan penetrasi yang cepat, Indonesia menjelma menjadi komoditas ekonomi digital terbesar di dunia, sehingga menarik untuk dikaji secara mendalam. Penelitian ini bertujuan mengukur faktorfaktor yang memengaruhi keputusan konsumen memilih hotel secara online yaitu variabel persepsi manfaat, persepsi kemudahan, dan persepsi risiko. Penelitian dilakukan terhadap pelanggan hotel yang bertransaksi melalui e-commerce Traveloka minimal satu kali. Metode penentuan sampel yang digunakan ialah teknik purposive/judgement sampling (non-probability sampling), dan jumlah yang memenuhi kriteria ditetapkan 106 responden. Hasil menunjukkan bahwa variabel persepsi manfaat dan persepsi kemudahan memiliki pengaruh positif dan signifikan terhadap keputusan e-commerce, sedangkan persepsi risiko tidak berpengaruh signifikan. Temuan ini berkontribusi terhadap peningkatan wawasan dan pemahaman para pelaku e-commerce, khususnya Traveloka dalam mengembangkan strategi yang jitu untuk meningkatkan keuntungan bisnis.
\end{abstract}

Kata Kunci: Persepsi Manfaat, Persepsi Kemudahan, Persepsi Risiko, Keputusan Pembelian Online, E-commerce.

\begin{abstract}
Clutching rapid penetration, Indonesia has transformed onto the biggest digital economic market throughout the world, hence it is interesting to be studied in depth. This study aims to measure factors that are considered affecting consumer online purchasing decisions which are perceived usefulness, perceived ease of use, and perceived risk. The study was conducted upon the hotel consumers who have performed online transaction via Traveloka for at least once. The sampling method used purposive sampling technique (non-probability sampling) and the number of respondents that met the criterion was set by 106 respondents. The result shows perceived usefulness and perceived ease of use have positive and significant effect on e-commerce decision, whereas perceived risk has not significant effect. The founding implicates for the improvement of new insights and better understanding to e-commerce actors, especially Traveloka by developing effective strategies to increase profit.
\end{abstract}

Keywords: Perceived usefulness, Perceived ease of use, Perceived risk, Online purchase decision, E-commerce.

How to Cite: Ashoer, M., Munawir, N.H., \& Fahrina, M. (2019). Analisis Faktor yang Mendorong Konsumen Memilih Hotel Melalui Situs Traveloka.com. Jurnal Konsep Bisnis dan Manajemen. 5 (2): 146-157 


\section{PENDAHULUAN}

Era globalisasi dan pelbagai kemajuan teknologi telah menciptakan keterbukaan atau transparansi terutama pada bidang pengembangan Information and Communication Technology (ICT) (Ashur, 2016). Seiring dengan perkembangan tersebut, kegiatan perdagangan barang/jasa melalui internet mulai muncul, literatur menyebutnya Electronic Commerce (e-commerce) (Fayad dan Paper, 2015; Gefen et. al., 2003). Singkatnya, e-commerce merupakan wadah untuk memfasilitasi proses transaksi berbagai jenis barang dan jasa melalui media internet. Tren ini tanpa terkecuali juga melanda Indonesia, hal tersebut tercermin lewat pertumbuhan jumlah pengguna internet yang meroket dalam satu dekade terakhir. Dalam skala dunia, Indonesia menempati urutan ke-5 jumlah pengguna internet terbesar dengan angka sekitar 145 juta (Internetworldstat, 2017). Dapat dibayangkan bagaimana masifnya aktivitas pengguna internet, dampaknya bahkan membawa pergeseran perilaku dari hanya sekedar mencari informasi menjadi transaksi bisnis
(Ashoer dan Said, 2016).

Terlepas dari deskripsi fenomena di atas, hasil riset Nielsen pada tahun 2016 tentang negara-negara di Asia Pasifik yang memanfaatkan internet sebagai media belanja online justru belum menguntungkan posisi pasar e-commerce Indonesia. Tercatat hanya 51\% responden yang menggunakan internet sebagai media belanja, terpaut jauh oleh Korea Selatan (98\%), kemudian disusul Jepang (97\%), Taiwan (93\%), China (83\%), India (78\%), Hong Kong (77\%), Malaysia (70\%), Thailand (61\%), Vietnam (58\%) (Nielsen, 2014). Survei ini mengindikasikan bahwa Indonesia relatif cukup tertinggal jika dikomparasikan secara apple to apple dengan negara tetangga lainnya dalam hal pemanfaatan e-commerce. Mengacu pada survei di atas, aspek pengalaman nampaknya memainkan peran vital dalam pengembangan e-commerce, semakin sering pengguna bertransaksi secara online, maka semakin baik pula keputusan pembelian online yang mereka ambil (Hong dan Cha, 2013). Semakin banyak penjual yang memasarkan barang/jasa 
secara online, maka semakin besar juga keinginan konsumen Indonesia untuk bertransaksi melalui toko online (online shop).

Pertimbangan yang dimiliki oleh konsumen sebelum memutuskan $e$ commerce penting untuk dipahami, maka faktor-faktor yang memengaruhi seperti kemudahan dalam memeroleh informasi mengenai produk, kemudahan dalam mengakses situs website, dan jaminan keamanan dari risiko transaksi online dianggap menjadi fokus utama yang laik untuk dikaji secara mendalam. Variabel tersebut diekstrak menggunakan konsep Technology Acceptance Model (TAM) dari Davis et al. (1986), kemudian dipadukan dengan studi Pavlou (2003) untuk memperoleh pemahaman yang komprehensif. Beberapa penelitian terdahulu juga telah menganalisis bagaimana TAM memengaruhi transaksi $e$ commerce, misalnya penelitian Gefen et al. (2003) tentang pembelian CD dan buku secara online terhadap siswa dan mahasiswa di Amerika Serikat, kemudian Luthfiadi dan Dewanto (2013) yang khusus mempelajari pola konsumsi pengguna portal e-commerce (sekaligus media sosial) yaitu Kaskus.com. Terakhir, Loanata dan Tileng (2016) yang menganalisa pembelian tiket pesawat online pada pengguna situs Traveloka.com. Penelitian di atas memiliki kesamaan pada model adopsi TAM, sedangkan kebaruan yang diangkat dalam studi ini ditekankan pada variabel dan objek penelitian yang dikhususkan pada pemilihan hotel melalui situs Traveloka.com. Landasan memilih objek berdasarkan tren e-commerce yang sedang naik daun saat ini, ditambah jumlah transaksi online khusus hotel di Traveloka mengalami peningkatkan yang signifikan sehingga mengukuhkan perusahaan tersebut sebagai pemimpin pasar. Berdasarkan alur argumentasi di atas, penelitian ini dipandang penting untuk mengkaji keputusan pembelian hotel pada situs Traveloka.com. Sebagai penelitian empiris, temuan diharapkan dapat memberikan pemahaman yang baru bagi pelaku e-commerce dalam menyusun strategi yang efektif.

E-commerce merupakan segala bentuk transaksi perdagangan/ perniagaan barang atau jasa dengan memanfaatkan media elektronik. Mc Leod dan Schell (2008) menyatakan bahwa $e$ commerce memungkinkan penggunaan internet dan komputer dengan browser Web untuk membeli dan menjual produk. Selain itu, e-commerce juga menawarkan 148 
lebih banyak alternatif pilihan produk kepada konsumen, mereka misalnya dapat memilih produk dari $e$-vendor yang sesuai dengan preferensi mereka. Beberapa kasus pada produk atau jasa yang telah digitized, e-commerce memangkas biaya waktu dan pengiriman (Turban et al., 2015 \& Ashoer, 2019).

Technology acceptence model (TAM) adalah salah satu model yang dibangun untuk menganalisis dan memahami faktor-faktor yang memengaruhi penerimaan penggunaan teknologi komputer. Model ini menjelaskan bahwa ketika penggunan disajikan dengan teknologi baru, sejumlah faktor akan memengaruhi keputusan mereka. Studi Luthfiandi (2012) menyatakan bahwa model yang dibangun untuk menganalisis dan memahami faktor-faktor diterimanya penggunaan teknologi, diantaranya ialah Theory of Reasoned Action (TRA), Theory of Planned behavior (TPB), dan Technology Acceptance Model (TAM).

Penjelasan ini didukung oleh pendapat Jogiyanto (2007) yang menyatakan, TAM merupakan pengembangan dari teori TRA untuk memberikan penjelasan tentang perilaku pemakai sistem informasi. Salah satu aspek yang dapat memengaruhinya adalah persepsi pengguna terhadap fitur kemanfaatan (usefulness) dan kemudahan penggunaan (ease of use) teknologi informasi sebagai suatu tindakan yang memiliki landasan dalam konteks penggunaan teknologi.

Kemudian dalam penelitian terdahulu dari studi Pavlou (2003) yang berjudul "Consumer Acceptence of Electronic Commerce: Integrating Trust and Risk with the Technology Acceptence Model". Pada technology perspective terdiri dari persepsi terhadap kemudahan dalam penggunaan (perceived ease of use), dan persepsi manfaat (perceived usefulness). Kedua konstruk tersebut bersumber dari model TAM, lalu diintegrasikan dengan kepercayaan dan persepsi risiko (perceived risk). Penelitian ini akan mengangkat 4 (empat) konstruk yang dimodifikasi mengacu pada beberapa penelitian terdahulu, yaitu: (1) keputusan pembelian online, (2) persepsi manfaat (perceived usefulness), (3) persepsi kemudahan (perceived ease of use) dan (3) persepsi risiko (perceived risk). Dengan demikian, kerangka konseptual dalam penelitian ini dapat dilihat dalam Gambar 1 berikut ini:

\section{Gambar 1}

Kerangka Konseptual Penelitian

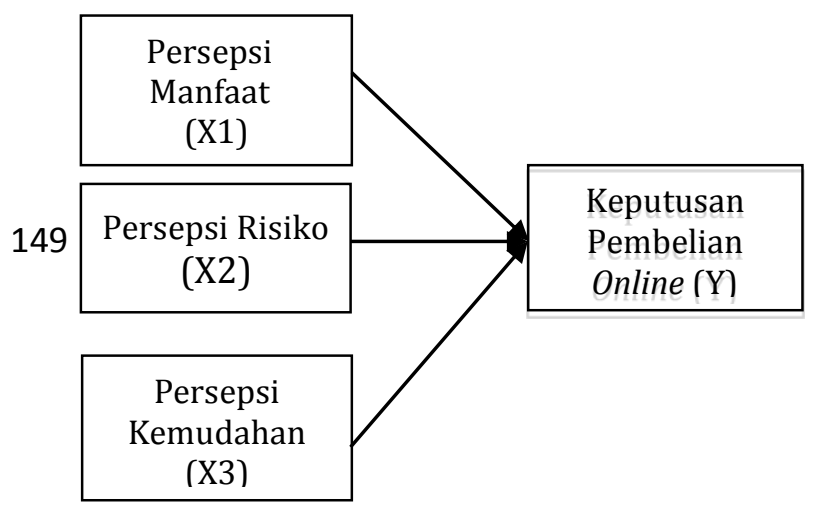


Berdasarkan alur pemaraparan di atas, maka hipotesis penelitian dirumuskan sebagai berikut:

H1: Persepsi manfaat (perceived usefulness) memiliki pengaruh terhadap keputusan pembelian online H2: Persepsi risiko (perceived risk) memiliki pengaruh terhadap keputusan pembelian online

H3: Persepsi kemudahan (perceived ease of use) memiliki pengaruh terhadap keputusan pembelian online.

\section{METODE PENELITIAN}

\section{Populasi dan Sampel}

Semua konsumen yang menggunakan layanan pemesanan hotel via situs e-commerce Traveloka merupakan populasi dalam penelitian ini. Perusahaan tersebut dipilih karena memiliki reputasi yang kredibel dalam menyajikan database hotel terlengkap di Indonesia. Mengingat banyaknya pelanggan Traveloka (sehingga tidak ditemukan angka mutlak), maka teknik sampling yang digunakan ialah purposive sampling, artinya hanya responden yang memiliki unsur dan kriteria yang relevan akan ditetapkan sebagai sampel (Zikmund et al., 2009). Kriteria sampel yang ditetapkan ialah konsumen yang telah melakukan pemesanan hotel melalui situs Traveloka.com minimal 1 (satu) kali. Pertimbangan tersebut diambil karena responden sudah mempunyai pengalaman dibandingkan dengan responden yang belum pernah bertransaksi via situs, sehingga memudahkan peneliti untuk mendapatkan data primer yang akurat. Teknik pengumpulan data menggunakan kuesioner elektronik yang dirancang menggunakan bantuan aplikasi Google Drive (www.google.com/drive). Kuesioner diseminasikan melalui e-mail dan media sosial mainstream lainnya (facebook, line, whatsapp).Mempertimbangkan pendapat Sekaran (2011) tentang jumlah sampel yaitu minimal 30 responden dalam metode non-probability sampling, maka jumlah memenuhi kriteria sampel ditetapkan sebanyak 106 responden.

\section{Definisi Operasional Variabel}

Definisi operasional variabel terdiri dari Persepsi Manfaat, Persepsi Risiko, Persepsi Kemudahan sebagai variabel independen (bebas) 150 
dependen (terikat) yaitu Keputusan Pembelian Online dilambangkan dengan (Y). Perceived Usefulness juga seringkali disebut dengan persepsi manfaat. Wibowo (2007) menyatakan persepsi manfaat sebagai ukuran (indikator) di mana teknologi informasi akan mendatangkan kenutungan bagi orang/ perusahaan yang menggunakannya. Indikator yang digunakan untuk mengukur variabel ini adalah kegunaan belanja online, dan efektivitas. Persepsi risiko (perceived risk) didefinisikan sebagai sebuah ketidakpastian yang dihadapi oleh konsumen ketika mereka tidak dapat meramalkan/ memroyeksikan dampak dari keputusan pembelian (Schiffman dan Kanuk, 2008). Indikator pengukuruan variabel ini meliputi 4 (empat) item yaitu risiko ekonomi (economic risk), risiko pribadi (personal risk), performa penjual (seller performance), dan risiko privasi (privacy risk). Persepsi kemudahan (perceived ease of use) didefinisikan Chin dan Todd (1995) sebagai ukuran kemudahan penggunaan atau pemahaman mengenai seberapa besar dampak adopsi penggunaan teknologi komputer yang dirasakan. Persepsi individu berkaitan erat dengan kemudahan dalam menggunakan situs website (perceived ease of use) pada tingkat dimana individu dapat memercayai bahwa mengakses situs tertentu akan terbebas dari kesalahan (sistem). Beberapa indikator pengukuran variabel ini meliputi isi mudah dipelajari, kemudahan penggunaan sesuai dengan keinginan pengguna, informasi mudah dipahami, dan mudah untuk berinteraksi.

Secara ringkas, variabel dan indikator penelitian masing-masing variabel dapat diamati dalam tabel 1 berikut ini: 
Tabel 1

Variabel dan Indikator Penelitian

\begin{tabular}{|c|c|c|c|}
\hline No & Variabel & Indikator & Sumber \\
\hline 1 & $\begin{array}{l}\text { Persepsi Manfaat (Perceived } \\
\text { Usefulness) }\left(\mathrm{X}_{\mathbf{1}}\right)\end{array}$ & $\begin{array}{l}\text { - Kegunaan belanja online } \\
\text { - Efektivitas }\end{array}$ & $\begin{array}{l}\text { Gefen et al. } \\
(2003)\end{array}$ \\
\hline 2 & Persepsi Risiko $\left(\mathrm{X}_{2}\right)$ & $\begin{array}{ll}\text { - } & \text { Resiko ekonomi } \\
\text { - } & \text { Resiko pribadi } \\
\text { - } & \text { Performa penjual } \\
\text { - } & \text { Resiko privasi }\end{array}$ & $\begin{array}{l}\text { Pavlou (2003); } \\
\text { Hong dan Cha } \\
\text { (2013) }\end{array}$ \\
\hline 3 & $\begin{array}{l}\text { Persepsi Kemudahan } \\
\text { Penggunaan } \\
\text { (Perceived Ease of Use) }\left(\mathrm{X}_{3}\right)\end{array}$ & $\begin{array}{l}\text { - } \text { Isi mudah dipelajari } \\
\text { - } \text { Kemudahan penggunaan } \\
\text { - } \text { sesuai dengan keinginan pengguna } \\
\text { - } \text { Informasi mudah dipahami } \\
\text { - } \\
\text { Kemudahan berinteraksi }\end{array}$ & $\begin{array}{l}\text { Gefen et al. } \\
(2003)\end{array}$ \\
\hline 4 & Keputusan Pembelian Online (Y) & $\begin{array}{l}\text { - Melakukan pembelian } \\
\text { - Perilaku pasca (setelah) pembelian }\end{array}$ & $\begin{array}{l}\text { Gefen et al. } \\
(2003) ; \text { Pavlou } \\
(2003)\end{array}$ \\
\hline
\end{tabular}

Sumber: Penelitian terdahulu

\section{Uji Instrumen}

Validitas adalah tingkat kesahihan terhadap alat ukur (indikator) yang digunakan. Instrumen dikatakan valid ketika alat ukur yang dipergunakan untuk mendapatkan data itu valid atau dapat digunakan untuk mengukur apa yang seharusnya diukur. Uji reliabilitas diterapkan untuk menetapkan apakah instrumen (kuesioner) dapat digunakan lebih dari satu kali, atau paling tidak digunakan oleh responden yang sama akan menghasilkan data yang konsisten.

\section{Uji Hipotesis}

Pengujian hipotesis dilakukan menggunakan uji F (simultan) dan uji T

(parsial). Uji F adalah pengujian secara simultan (bersama-sama) untuk mengetahui adanya pengaruh antara

variabel bebas yaitu persepsi manfaat, pesepsi risiko, dan persespsi kemudahan penggunaan terhadap variabel terikat yaitu pembelian online. Sedangkan uji $\mathrm{t}$ adalah pengujian yang digunakan untuk mengukur pengaruh dari masingmasing variabel independen terhadap variabel dependen. 


\section{HASIL DAN PEMBAHASAN}

Ringkasan hasil uji pengolahan data primer menggunakan program SPSS versi 24.00 dirangkum dalam Tabel 2 berikut ini;

Tabel 2 Ringkasan Hasil Uji

\begin{tabular}{|l|c|c|c|c|}
\hline Variabel & Beta & $\mathrm{T}$ & Sig. & Keterangan \\
\hline Persepsi Manfaat (X1) & .434 & 3.295 & .000 & Signifikan \\
\hline Persepsi Risiko (X2) & .161 & 1.166 & .132 & Tidak Signifikan \\
\hline Persepsi Kemudahan (X3) & .235 & 2.020 & .001 & Signifikan \\
\hline Adjusted R Square (R $)=0,448$ & \\
\hline ttabel & $=1,671$ \\
\hline Fhitung Sig F & $=13,789$ \\
\hline Ftabel & $=0,000$ \\
\hline Alfa & $=2,76$
\end{tabular}

Sumber : Data Primer 2018 (diolah)

\section{Koefisien Determinasi}

Nilai koefisien determinasi $\left(R^{2}\right)$ dapat diartikan dengan kontribusi perubahan variabel independen yang mampu dijelaskan oleh variasi perubahan variabel dependen. Berdasarkan perhitungan, terdapat pengaruh variabel independen terhadap variabel dependen. Hal ini ditunjukkan pada koefisien determinasi sebesar 0,448. Artinya variabel independen mampu menjelaskan $44,8 \%$, sementara selisihnya yaitu 55,2\% dipengaruhi oleh variabel lain yang tidak diangkat dalam penelitian.

\section{Uji Hipotesis (Uji F dan Uji T)}

Pengujian hipotesis dapat dilihat melalui hasil uji $\mathrm{F}$ (simultan) dan uji $\mathrm{T}$ (parsial). Pembuktiannya mengacu pada kriteria signifikansi jika Fhitung $>$ Ftabel dan probabilitas $($ alfa $)<0,05$. Berdasarkan hasil perhitungan uji regresi liner berganda nilai Fhitung menunjukkan nilai sebesar 13,789 (signifikansi F= 0,000). Jadi Fhitung $>$ Ftabel (13.789 > 2,76) atau Sig. F < 5\% $(0,000<0,05)$. Artinya, secara simultan variabel terukur yaitu Persepsi Manfaat (X1), Persepsi Risiko (X2), dan Persepsi Kemudahan (X3) berpengaruh positif dan signifikan terhadap variabel Keputusan Pembelian Online (Y).

Uji T digunakan untuk mengukur pengaruh setiap variabel independen terhadap variabel dependen. Berdasarkan 
ringkasan uji regresi bergandan yang tercantum pada tabel 2 di atas, maka dapat ditarik beberapa kesimpulan:

Variabel Persepsi Manfaat (X1) memiliki nilai ${ }^{\mathrm{T}}$ hitung sebesar 3,295 dan probabilitas 0,000. Karena ${ }^{\mathrm{T}}$ hitung $>\mathrm{T}$ tabel $(3,295>1,671)$ atau sig < 5\% $(0,000<$ 0,05) maka Persepsi Manfaat (X1) berpengaruh positif dan signifikan terhadap Keputusan Pembelian Online (Y). Dengan demikian, H1 Diterima.

Variabel Persepsi Risiko memiliki nilai ${ }^{\mathrm{T}}$ hitung sebesar 1,166 dan probabilitas 0.132 . Karena ${ }^{\mathrm{T}}$ hitung $<{ }^{\mathrm{T}}$ tabel $(1,166<1,671)$ atau sig < 5\% (0.132< 0,05) maka Persepsi Risiko (X2) berpengaruh positif namun tidak signifikan terhadap Keputusan Pembelian Online (Y). Dengan demikian, H2 Ditolak.

Variabel Persepsi Kemudahan Penggunaan (X3) memiliki nilai Thitung sebesar 2.020 dan probabilitas 0.001 . Karena ${ }^{\mathrm{T}}$ hitung $>\mathrm{T}$ tabel $(2,020>1,671)$ atau sig $<5 \%(0.001<0,05)$ maka variabel Persepsi Kemudahan Penggunaan (X3) berpengaruh positif dan signifikan terhadap Keputusan Pembelian Online (Y). Dengan demikian, H3 Diterima.

\section{Pembahasan}

Hasil pengujian menjelaskan bahwa variabel-variabel yang diteliti memberikan kontribusi terhadap keputusan konsumen memilih hotel melalui situs Traveloka.com. Persepsi manfaat (X1) merupakan variabel yang paling dominan memengaruhi pengambilan keputusan konsumen. Koefisien jalur ( $\beta$ standardized) dari variabel ini mempunyai nilai yang paling tinggi yaitu sebesar 0.413. Hal ini mengindikasikan bahwa konsumen sangat memerhatikan aspek kemanfaatan sebuah layanan situs. Indikator pengukuran X1 meliputi kegunaan dan efektifitas dari media pembelian produk/ jasa melalui ecommerce. Konsumen Traveloka merasa bahwa sarana yang ditawarkan situs sangat berguna bagi mereka dalam mendapatkan informasi hotel yang mereka inginkan. Disamping itu, adanya media transaksi pembelian melaui e-commerce, dinilai responden merupakan media yang sangat efektif dalam menunjang proses transaksi. Informasi hotel yang mereka butuhkan, dapat diakses dengan mudah melalui sarana e-commerce. Dengan demikian, variabel persepsi manfaat dijadikan sebagai acuan utama bagi konsumen Traveloka sebelum memilih hotel via website.

Persepsi risiko (X2) merupakan variabel yang tidak berpengaruh signifikan terhadap keputusan konsumen memilih 
hotel melalui Traveoka.com. Artinya, variabel ini tidak dijadikan landasan yang utama bagi konsumen dalam memilih hotel secara online. Hal ini dimungkinkan terjadi mengingat responden terdiri dari konsumen yang telah memiliki pengalaman dalam melakukan pembelian online melalui situs, sehingga tingkat kekhawatiran konsumen cenderung rendah. Dimensi variabel persepsi risiko meliputi risiko ekonomi, risiko pribadi, performa penjual, dan risiko privasi dinilai kurang begitu memberikan dampak yang berarti dalam keputusan transaksi $e$ commerce konsumen Traveloka. Dari keempat dimensi tersebut, performa penjual merupakan dimensi yang paling disetujui atau paling menonjol oleh konsumen Traveloka sebagai faktor dalam menentukan pilihan. Selain itu, risiko lainnya seperti pribadi, menjadi faktor mengapa konsumen tidak tertarik dalam melakukan pembelian, dikarenakan adanya kerugian bagi pribadi konsumen, karena barang/ jasa yang dibeli tidak sesuai dengan ekspektasi responden Traveloka, menyebabkan konsumen enggan untuk membeli lagi di toko online tersebut. Dengan demikian, variabel ini dianggap tidak menjadi acuan utama bagi responden dalam memilih hotel melalui Traveloka.

$$
\text { Persepsi kemudahan }
$$

berpengaruh positif dan signifikan terhadap keputusan konsumen melakukan pemesanan hotel di situs Traveloka.com. Aspek ini dipersepsikan positif dan dinilai sebagai salah satu acuan bagi responden dalam mengambil keputusan pembelian hotel secara online melalui media internet atau e-commerce. indikator dari variabel ini terdiri dari mudah untuk dipelajari bagi konsumen, di mana secara langsung menggiring mereka dalam melakukan transaksi pembelian yang mereka minati atau mereka butuhkan. Media online seperti jejaring sosial facebook, dan sejenisnya juga sangat mudah dipelajari oleh responden khususnya kalangan terpelajar yaitu mahasiswa. Mereka dapat dengan cepat beradaptasi dengan internet, menjadikan mereka tidak begitu menemukan kesulitan dalam bertransaksi di Traveloka.

\section{SIMPULAN}

Hasil penelitian yang telah dipaparkan sebelumnya, diketahui terdapat pengaruh secara simultan dari variabel-variabel independen yaitu persepsi manfaat (X1), persepsi risiko (X2), dan persepsi kemudahan penggunaan (X3) terhadap Keputusan konsumen (Y) memilih hotel melalui Traveloka. Dari ketiga variabel yang diteliti, terdapat dua variabel yaitu persepsi manfaat (X1) dan persepsi kemudahan (X3) yang berpengaruh positif 
dan signifikan, sementara persepsi risiko (X2) tidak memilki pengaruh signifikan terhadap keputusan pembelian online.

Hasil penelitian diketahui bahwa prioritas utama pelanggan Traveloka dalam e-commerce ialah asas manfaat (variabel persepsi manfaat), di mana indikator pengukuran ialah nilai guna dan efektivitas. Atribut ini sangat diperhatikan oleh konsumen sebelum melakukan keputusan transaksi hotel secara online. Persepsi risiko menjadi variabel yang tidak berpengaruh atau tidak dipertimbangkan sebagai acuan utama bagi pelanggan Traveloka. Namun demikian, perusahaan $e$ commerce lainnya juga perlu memperhatikan variabel ini kedepannya, mengingat kondisi yang selalu dinamis dari persepsi netizen selaku konsumen dimasa yang akan datang.

Bagi peneliti selanjutnya diharapkan meneruskan penelitian ini dengan menggunakan variabel-variabel lainnya di luar penelitian ini, mengingat masih ada kemungkinan besar variabel-variabel lain yang berpengaruh terhadap mahasiswa selaku konsumen dalam mengambil keputusan pembelian secara online. Bagi para penjual online yang ingin menawarkan produknya melalui toko online, mereka dapat mementingkan aspek seberapa besar manfaat dan kemudahan yang akan dirasakan oleh konsumen. Penjual online dapat menonjolkan kualitas situs karena dengan website yang memberi berbagai info produk, kemudahan dalam mengakses, layanan interaksi penjual yang cepat tanggap akan memengaruhi keputusan pembelian online konsumen secara signifikan

\section{DAFTAR PUSTAKA}

Ashur, M. (2016). Pengaruh Dukungan Sosial, Persepsi Risiko dan Interaksi Sosial terhadap Kepercayaan Dan Niat Pembelian Konsumen Pada Media S-Commerce (Studi Pada Konsumen S-Commerce Di Indonesia). Jurnal Bisnis dan Manajemen, Vol. 3, No.1.

Ashoer, M \& Said, S. (2016). The effect of perceived risk on consumer's purchase intention in s-commerce websites; an empirical evidence from Indonesia. Proceedings of the International Conference on Accounting, Management, Economics and Social Sciences (ICAMESS). ISBN: 978-602-73705-0-0.

(http://icamess.feb.unsika.ac.id/201 6/03/31/the-effect-of-perceivedrisk-on-consumers-purchaseintention-in-s-commerce-websitesan-empirical-evidence-fromindonesia/).

Ashoer, M. (2019). Pengaruh E-Service Quality Terhadap E-Satisfaction Pada Pelanggan Situs Toko Online Brodo. Jurnal Bisnis, Manajemen, dan Informatika, 15(3), 238-251.

Davis, F.D. (1989). "Perceived Usefulness, Perceived Ease of Use, and User Acceptance of Information 
Technology". MIS Quarterly.Vol. 13 No. 5, pp.319-339.

Fayad, R. \& Paper, D. (2015). The Technology Acceptance Model ECommerce Extension: A Conceptual Framework. Procedia Economics and Finance. Vol.26. pp.1000 - 1006.

Gefen, D., Karahanna. E. \& Straub, D.W. (2003). Trust and TAM in online shopping: An integrated model. MIS Quarterly. Vol. 27, Iss.1, pp. 51-90.

Hong, B. \& Cha, S. H. (2013). The mediating role of consumer trust in an online merchant inpredicting purchase intention. International Journal of Information Management, Vol.33, pp.927-939.

InternetWorldStats. (2018). Top 20 countries with the highest number of internet users.

(https://www.internetworldstats.co m/top20.htm, Diakses 4 Maret 2018).

Jogiyanto. (2007). Model Kesuksesan Sistem Teknologi Informasi. Yogyakarta: Andi.

Loanata, T \& Tileng, G.K. (2016). Pengaruh Trust dan Perceived Risk pada Intention to Use menggunakan Technology Acceptance Model (Studi Kasus pada Situs E-Commerce Traveloka). Jurnal Informatika dan Sistem Informasi (JUISI), Vol.2, No.1, hal.64-73.

Luthfiadi, M. \& Dhewanto, W. (2013). Technology Acceptance of Ecommerce in Indonesia. International Journal of Engineering Innovation and Management, Vol.3.

McLeod, R. \& Schell, Jr., G. P., (2008), Management Information System, Edisi 10. Jakarta: Salemba Empat.

Nielsen. (2016). E-commerce Global Report (https://www.nielsen.com/content/ dam/nielsenglobal/ip/docs/report/ 2016/Nielsen-Global-ConnectedCommerce-Report-Ianuary-2016 Diakses 4 Maret 2018).

Pavlou, P. A. (2003). Consumer Acceptance of Electronic Commerce: Integrating
Trust and Risk with the Technology Acceptence Model. International Journal of Electronic Commerce, Vol.7, Iss.3, pp.101-134.

Sekaran, Uma. (2011). Research Methods for Business, Buku 2, Edisi 1 dan 2. Salemba Empat. Jakarta.

Schiffman, L \& Kanuk, L.L. (2008). Perilaku Konsumen, edisi ketujuh. Jakarta: Indeks.

Turban, E., King, D., Lee, J.K., Liang, T.-P., \& Turban, D.C. (2015). Electronic Commerce: A Managerial and Social Networks Perspective. Springer International Publishing: Switzerland.

Zikmund, William G., Barry J. Babin, Jon C. Carr, Mitch Griffin. (2009). Business Research Methods. Edisi 8. SouthWestern College. 